\title{
A Survey of Emotional Response for Affective Writing Measurement
}

\author{
Yu Cheng Shen $1, a^{*}$ \\ ${ }^{1}$ Qujing Normal University, Yunnan Province, China \\ aroscoeshen@gmail.com \\ * The Corresponding Author
}

Keywords: Emotional Response; Affective Writing; Cognitive Learning

\begin{abstract}
Educators are familiar with the three domains of learning: (1) cognitive, (2) affective, and (3) psychomotor. The instructional and assessment strategies are typically focused on the cognitive domain of learning because of the difficulty in measuring gains in the affective domain during the teaching process. The purpose of this study was to measure affective learning and writing about the experience. Research is devoid of writing as an assessment tool to measure learning in the affective domain. Totally, 142 individuals were selected to assess psychometric properties. Factor analysis extracted was used in this process. The factors plays important implications for conducting research sensitive to writing and emotional intelligence.
\end{abstract}

\section{Introduction}

Taylor, Marienau, \& Fiddler [1] stated emotional dimension of transformational learning was built. In addition, the development of people in many dimensions as they relate is to learning including the emotional, cognitive, social, psychological, and biological domains. Hence, Fischer and Fischer [2] suggested that emotional intelligence may positively increase in a treatment group over and above a non-equivalent control group. Positive significant differences were reported from pre- to post-test on an emotional intelligence measure [3] after experiencing a semester-long curriculum of reading and responding to literature designed to increase emotional intelligence abilities. The changes recorded by the self-report measure were congruent with the positive results of a pre- and post-test administration of a behavioral measure involving students responding in writing to an emotionally laden video. Although the work of Fischer and Fischer [2] was significant, it was not sensitive enough to identify factors underlying the participants in the treatment group's response to the emotional literature. Studying emotions in response to literature is a new dimension of emotional intelligence and requires a more refined approach. Evolving from the research on emotional intelligence and the use of literature to enhance the emotional quotient as a significant dimension of adult education, this study investigated the development and validation of an instrument designed to measure people's emotional responses to writing. More specifically, the purpose of this study was to create a new psychological instrument, the Affective Cognition Writing Survey (ACWS). The research question of the study was as follow one: To what degree can a psychological measure of emotional responses to writing be developed and validated?

\section{Literature Review}

When we think about beliefs and attitudes, we are on a less trodden path called the affective domain of learning. Researchers studying human behavior recognize the need to consider both cognitive and affective dimensions of learning, and their interrelationships [4] [5] [6]. Perhaps the first step on this path is to operationally define these terms. "Affect" is often described with words such as feelings, emotions, motivations, attitudes, and beliefs. Studies have noted relationships exist between moods and information storage and retrieval[7]. There is evidence that affect can directly influence cognition. 
Several studies describe relationships between a student's mood and learning, as well as relationships between moods and information storage and retrieval [8] [9] [10] [11].Hatton and Smith[12] identified four types of reflective writing done by students. The first is descriptive writing (not reflective) where the student simply describes the events. Students may begin their reflective writing in this manner to set the stage for further discussion. Unfortunately, some students never get beyond this stage [12]. The next type, descriptive reflection, uses the student's personal judgment in descriptive reflection of an event. A student might cite personal reasons for choosing a particular theory or position at this level. In dialogic reflection, students engage in conversation with themselves where they explore possible reasons for the event. The most in-depth level is critical reflection. At this level, the student provides reasons for the event in the broader social, political, or historical contexts. Writing is a fundamental part of the reflection process [13].

\section{Method}

This study investigated the relationship of different factors affecting individuals' emotional intelligence in writing by the Affective Cognition Writing Survey.

1.Participants: 142 people participated in the study included 44 men (31\%) and 88 women (66\%) with 10 people not reporting gender. The participants had a mean age of $21.0(\mathrm{SD}=6.6)$ with a range of 17 to 53. Most students, 65\% ( $\mathrm{n}=93)$, reported their class level as Freshman, 8\% $(\mathrm{n}=11)$ Sophomore, 6\% $(n=9)$ Junior, $8 \%(n=11)$ Senior, and 4\% $(n=5)$ Graduate Student, with 9\% $(n=13)$ not reporting.

2.Instrumentation Convergent Validity. One instrument was used to provide convergent validity for the Affective Cognitive Writing Survey (ACWS). The Affective Content in Literature Survey (ARLS) (Fischer \& Fischer, 2005) measure was used to provide a modest convergence with the ACWS. The ARLS measure was designed to measure a person's emotional responses to literature. The ability to manage one's emotions is a part of the definition of friendship. The ARLS measure had excellent internal consistency (Cronbach's Alpha $=.92)$ and high test-retest reliability $(r=.92, p<.01)$.

3.ACWS Item Development. A review of literature concerning emotional intelligence provided a wealth of information from which items concerning identification and management of emotions emerged (Davis, Stankov, \& Roberts, 1998; Goleman, 1995; Jerabek, 2000; and Mayer, Caruso, \& Salovey, 1999). Accordingly, a review of literature concerning the emotional affects of literature stimulated the development of items concerning readers' reactions to the emotional content of poems, short stories, and novels (Cupchik, Leonard, Axelrad, \& Kalin, 1998; Graesser, Singer, \& Trabasso, 1994; and Suh \& Trabasso, 1993).Subsequently, items were then formatted into a Likert type scale, where $1=$ almost never; $2=$ rarely; $3=$ sometimes; $4=$ often; and $5=$ most of the time.

4.Content Validity: Initially, 25 items were developed for the Affective Response to Literature Survey and were rated for inclusion by 10 professionals, five with expertise in the field of psychology and the others in literature. The experts had a mean age of 51.7 years $(\mathrm{SD}=7.8), 50 \%$ had a doctorate and the others a master's degree, $90 \%$ were female. The experts had a mean of 19.1 years $(\mathrm{SD}=10.4)$ working as professionals. The professionals reviewed each of the items using the following scale: $1=$ essential, $2=$ useful but not essential, and $3=$ not essential. The following formula was then used to compute the validity ratio:

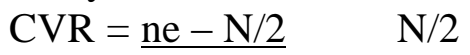

In this formula CVR = content validity ratio, ne = number of professionals indicating the items as "essential," and $\mathrm{N}=$ total number of professionals. For significance at the .05 level and inclusion in the ARLS, each item would have met the criteria of a CVR of .62 or higher.

\section{Result and Discussion}

Means and standard deviations for the 18 items in the ACWS can be seen in Table 1. The ACWS demonstrated high internal consistency (Cronbach's alpha $=.88$ ). Additionally, it demonstrated high test-retest reliability $(r=.90, \mathrm{p}<.001)$. Convergent construct validity for the ARLS was evidenced via 
correlations with relevant factors as seen in Table 2. As hypothesized very modest to modest correlations were computed for the ACWS and the corresponding measures of interest in writing, Number of Books Read/Year, Number of Books Read/Month, and Number of Books Read/Week. The construct represented by the ACWS would share some properties of the other constructs but not to a high degree.To find evidence of discriminate construct validity, a varimax rotated factor analysis was carried out determine subscales within the ACWSS (Huck, 2000). Six factors were extracted using principal component analysis as seen in Table 3.

Table 1 Means and standard deviations for ACWS items

\begin{tabular}{|l|l|l|}
\hline Item & Mean & $\begin{array}{l}\text { Standard } \\
\text { Deviation }\end{array}$ \\
\hline 1. Writing lets me express my feelings & 4.15 & .89 \\
\hline 2. Writing gives me a clearer understanding of the feelings I am having & 3.73 & 1.04 \\
\hline $\begin{array}{l}\text { 3. I tend to use a specific form of writing to express my emotions (i.e., a journal, or } \\
\text { poetry or e-mails, or letters, or a diary, etc.) }\end{array}$ & 3.55 & 1.12 \\
\hline 4. Writing allows me to share my feelings with others. & 3.69 & 1.16 \\
\hline 5. I include personal experiences that I feel are important in my writing. & 4.10 & .72 \\
\hline 6. Writing helps me process my feelings. & 3.82 & .99 \\
\hline 7. I usually enjoy my writing experiences. & 3.46 & 1.00 \\
\hline 8. I enjoy writing when I am expressing the things I care about. & 4.24 & .84 \\
\hline 9. I enjoy writing when I am exploring the things related to my life. & 4.03 & .85 \\
\hline $\begin{array}{l}\text { 10. I try to find a way to feel some satisfaction even when the writing project has } \\
\text { little appeal to me }\end{array}$ & 3.54 & 1.08 \\
\hline 11. I enjoy writing because of the insights that come to me while I am writing. & 3.57 & 1.08 \\
\hline 12. I usually feel pleased when I complete a writing project. & 3.81 & 1.02 \\
\hline $\begin{array}{l}\text { 13. When writing, I try to use both emotional appeals and logical reasoning to make } \\
\text { my points. }\end{array}$ & 3.90 & .79 \\
\hline 14. The success of my writing depends upon the emotional energy I bring to it. & 3.99 & .86 \\
\hline 15. When writing, I allow myself the freedom to contradict myself. & 3.70 & .91 \\
\hline $\begin{array}{l}\text { 16. In my writing, I mention my doubts by stating the things I have questions but no } \\
\text { answers for. }\end{array}$ & 3.70 & .94 \\
\hline $\begin{array}{l}\text { 17. I can risk writing things I have doubts about because I can always make } \\
\text { qualifying explanations on those views as I write. }\end{array}$ & 3.56 & .89 \\
\hline 18. Writing helps me build relationships with others & 2.78 & 1.01 \\
\hline 19. I write with an audience in mind & 3.33 & 1.06 \\
\hline 20. I imagine how a reader will respond to my writing & 3.54 & 1.03 \\
\hline $\begin{array}{l}\text { 21. I re-write or re-word things that will likely offend my reader so they come out } \\
\text { less offensive. }\end{array}$ & 3.46 & 1.02 \\
\hline $\begin{array}{l}\text { 22. When making strong points, I purposely write in a way that holds my reader's } \\
\text { attention long enough to read all of what I have to say. }\end{array}$ & 3.85 & .70 \\
\hline & & \\
\hline
\end{tabular}

The Affective Response to Literature Survey (ARLS) was a psychological measure developed and validated as a sensitive tool to more closely understand the emotional experiences of people in connection to literature. The ARLS was developed through a rigorous process that assisted in the validation of its content and readabilty. Furthermore, the items that remained after the process proved to have high internal consistency and test/retest reliability. To determine the instrument's construct validity, its relationships with a number of factors were analyzed. The ARLS showed positive correlations with measures of Friendship, Relationships, interest in Literature, number of books read per year, month and week. The most important analysis of the research was the identification of four underlying factors of the ARLS: Reflective Synthesis, Acting with Volition, Processing, and Empathetic Responding. The ARLS may help readers to more fully understand themselves and give direction for them to enhance their personal growth in this area of study. 
Table 2 Correlations of relevant measures

\begin{tabular}{|l|l|l|l|l|l|l|l|}
\hline Measure $^{1}$ & 1 & 2 & 3 & 4 & 5 & 6 & 7 \\
\hline 1 & & $.27^{*}$ & $.29^{*}$ & $.49^{*}$ & $.23^{*}$ & $.29^{*}$ & $.36^{*}$ \\
\hline 2 & & & $.64^{*}$ & .10 & .01 & .05 & .02 \\
\hline 3 & & & & .13 & .09 & .11 & .15 \\
\hline 4 & & & & & $.48^{*}$ & $.55^{*}$ & $.51^{*}$ \\
\hline 5 & & & & & & $.86^{*}$ & $.71^{*}$ \\
\hline 6 & & & & & & & $.88^{*}$ \\
\hline 7 & & & & & & & \\
\hline
\end{tabular}

Measure $^{1} 1=$ ARLS, $2=$ Friendship, $3=$ Relationships,

4=Interest in Literature, $5=$ No. of Books Read/Year,

$6=$ No. of Books Read/Month, 7 = No. of Books Read/Week

Table 3 Factor analysis of ACWS

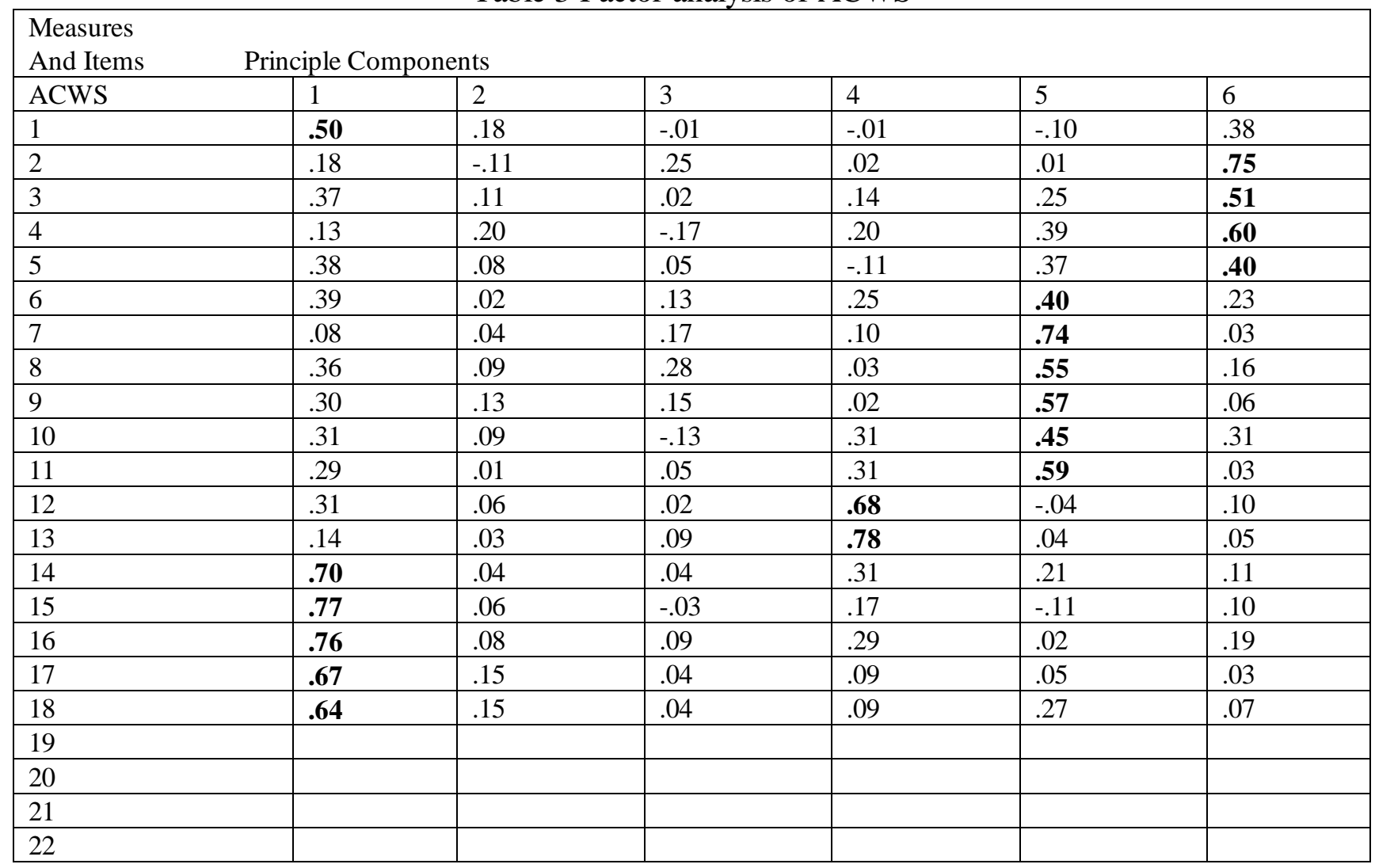

\section{Conclusion}

Through a rigorous process, research has found the ARLS to be a viable instrument, but recognizes that it needs further evidence of its validity. It can be concluded that it has substantial psychometric properties of reliability and validity. It may be used for a more sensitive exploration of use of the emotional content in literature within the transformational learning process.

\section{Acknowledgements}

This research is support by Qujing Normal University Social Science Grant 2016JY004 \& 2017 JZ002.

Yu-Cheng (Roscoe) Shen, Taiwan resident, doctoral degree in University of Idaho (USA), is an associate professor of Teacher Education College at Qujing Normal University, China. His research interests include the development and implementation of curriculum instruction, and the use of technology for the teaching and learning. 


\section{References}

[1] K. Taylor, C. Marienau, \& M. Fiddler.. Developing adult learners: Strategies for teachers and trainers. San Francisco: Josey-Bass, 2000.

[2] R.G. Fischer, \& J.M. Fischer. The development, testing, and evaluation of an emotional intelligence curriculum. MPAEA Journal of Adult Education, 2003, 32(1), 7-17.

[3] http://www psych tests.com/tests/iq/emotional_iq_r2_accessl.html.

[4] W. McKeachie. Psychology inAmerica's bicentennial year. American Psychologist,1976, 31, 819-833.

[5] S. H. McLeod. (1991). The affective domain and the writing process: Working definitions. JAC, 1991,11(1).

[6] L.Vygotsky. Thought and language. Cambridge, MA: MIT Press (1962).

[7] G.Bower. Mood and memory. American Psychologist,1981, 36, 129-148.

[8] T. Bastick. Intuition: How wethink and act. New York: John Wiley and Sons (1982).

[9]G. Bower, \& P.R. Cohen. Emotional influences in memory and thinking: Data and theory. Hillsdale N.J.: Erlbaum, 1982, pp.291-331.

[10] Ed. D. Kuiken. Mood and memory: Theory, research, and application. Newbury Park, CA: Sage (1991).

[11] W. N.Morris. Mood: The frame of mind. New York: Springer (1989).

[12] N. Hatton, \& D.Smith. Reflection in teacher education: Towardsdefinition and implementation. TheUniversity of Sydney: School of Teaching and Curriculum Studies (1995).

[13] J.Walkington, H.P.Christensen, \& H.Kock. (2001). Developing critical reflection as a part of teaching training and teaching practice. European Journal ofEngineering Education, 2001,26(4), 343-350. 